P-ISSN 2580 - 7781

E-ISSN 2615 - 3238

\title{
ANALISIS FAKTOR PEMBELIAN MOBIL BERDASARKAN HARGA DAN MEREK
}

\section{ANALYSIS OF CAR PURCHASE FACTORS BASED ON PRICES AND BRANDS}

\author{
Dewi Siska Simanjuntak \\ Pascasarjana Ilmu Ekonomi, Fakultas Ekonomi dan Bisnis, Universitas Sumatera Utara \\ dewisiskasimanjuntak@gmail.com
}

\begin{abstract}
ABSTRAK
Penelitian ini bertujuan untuk mengetahui pengaruh harga dan merek terhadap keputusan pembelian mobil Daihatsu pada PT. Daya Adicipta Wihaya Medan. Penelitian ini dilaksanakan di PT. Daya Adicipta Wihaya Medan dengan obyek penelitian dibatasi hanya terhadap variabel harga dan merek sebagai variabel bebas dan keputusan pembelian sebagai Variabel terikat. Sampel dalam penelitian ini adalah konsumen sebanyak 69 responden yang dihitung dengan menggunakan rumus Arikunto. Metode analisis yang digunakan pada penelitian ini adalah metode analisa kuantitatif. Metode pengumpulan data yang digunakan penelitian ini adalah kepustakaan, penelitian lapangan, yaitu angket (kuesioner), observasi (pengamatan). Adapun tahap tahap pengujiannya adalah uji validitas, realibilitas, asumsi klasik, dan analisis regresi linear berganda. Dari hasil penelitian diperoleh pertama, variabel harga berpengaruh signifikan terhadap keputusan pembelian. Kedua,variabel merek berpengaruh signifikan terhadap keputusan pembelian. Ketiga, variabel harga dan merek berpengaruh signifikan terhadap keputusan pembelian. Dan diperoleh angka $\mathrm{R}^{2}$ (R Square) sebesar 0,666 atau (66,6\%). Kesimpulan dari penelitian adalah ada pengaruh harga dan merek terhadap keputusan pembelian mobil Daihatsu pada PT. Daya Adicipta Wihaya Medan. Disarankan kepada perusahaan sebaiknya mempertimbangkan harga dalam menjual produk sehingga diharapkan konsumen memiliki informasi yang jelas dalam mengambil keputusan dalam pembelian produk. Perusahaan sebaiknya mempertimbangkan merek dalam menjual produk sehingga diharapkan konsumen memiliki informasi yang jelas dalam mengambil keputusan dalam pembelian produk. Konsumen sebaiknya mempelajari dan mencari informasi yang jelas mengenai harga dan merek suatu produk dalam mengambil keputusan untuk melakukan pembelian.
\end{abstract}

Kata Kunci :Harga, Merek, KeputusanPembelian.

\begin{abstract}
Purchasing decisions by consumers are decisions that involve perceptions of quality, value and price. Consumers not only use price as an indicator of quality, but also as an indicator of the costs that are exchanged for a product or product benefit. This study aims to determine the Influence of Prices And Brands Against Daihatsu Car Buying Decision at PT. Daya Adicipta Wihaya Medan.Analisa data is a quantitative analysis. Population and sample in this research is consumer which amounted to 69 people.The result of this research is $t$ value $>t$ table (7.506> 1.66792) means that there is partially significant influence between Price with purchase decision. The value of $t$ arithmetic $>t$ table (1.936> 0.67933 means partially there is significant influence between Brand (X2) with Purchase Decision $(Y) F$ value count $>F$ table (65.915> 3.14), meaning there is significant influence between (price and Brand) Collectively to the dependent variable
\end{abstract}


P-ISSN $2580-7781$

E-ISSN 2615 - 3238

(Purchase Decision). Based on the above table obtained the number R2 (R Square) of 0.666 or (66.6\%). Conclusion is no Effect of Prices And Brands Against Daihatsu Car Buying Decision at PT. Daya Adicipta Wihaya Medan .. It is advisable to the Company should consider the price ink sell products so that consumers are expected to have clear information in making decisions in purchasing products. Companies should consider the brand in selling products so consumers are expected to have clear information in making decisions in purchasing products. Consumers should study and seek clear information about the price and brand of a product in making a decision to make a purchase.

Keywords: Price, Brand, Purchase Decision

\section{PENDAHULUAN}

Saat ini perkembangan teknologi dunia khususnya industri otomotif memang terus mengalami kemajuan yang sangat pesat. Hal ini bisa dilihat dari besarnya kebutuhan masyarakat akan kendaraan pribadi yang bisa memudahkan perjalanan dekat maupun jauh. Pasar mobil di indonesia banyak sekali perusahaan yang menawarkan berbagai pilihan dengan harga dan merek yang bersaing untuk menarik perhatian para konsumen yang menjadi pertimbangan penting dalam memilih sebuah produk mobil salah satu nya adalah merek Daihatsu yang dikenal laris di Indonesia.

Pasar otomotif Indonesia mengalami lompatan tertinggi pada 2010 lalu, yang tumbuh sebesar 57, 3 persen dari 486. 088 unit pada tahun sebelumnya, menjadi 764. 710 unit. Tren pertumbuhan itu terus berlangsung dalam kurun waktu tiga tahun berikutnya, hingga mencapai rekornya 1. 229. 811 unit pada 2013.

Konsumen saat ini sangatlah kritis dalam memilih suatu Produk, keputusan untuk membeli suatu produk sangat dipengaruhi oleh penilaian akan bentuk kualitas produk tersebut. Tuntutan permintaan akan sebuah produk yang semakin berkualitas membuat perusahaan yang bergerak diberbagai bidang usaha berlomba-lomba meningkatkan kualitas produknya demi mempertahankan citra merek produk yang mereka produksi. Merek mempunyai sifat khas, dan sifat khas inilah yang membedakan produk yang satu berbeda dengan produk yang lainnya walaupun sejenis.

Keputusan pembelian oleh konsumen adalah keputusan yang melibatkan persepsi terhadap kualitas, nilai dan harga. Konsumen tidak hanya menggunakan 
harga sebagai indikator kualitas, tetapi juga sebagai indikator biaya yang ditukarkan dengan produk atau manfaat produk. Disini dapat dilihat sejauh mana harga dan merek dapat mempengaruhi keputusan pembelian konsumen dari Produk Mobil tersebut.

Keputusan pembeli juga dipengaruhi oleh karakteristik pribadi. Karakteristik pribadi meliputi usia dan tahapan dalam siklus hidup, pekerjaan, keadaan ekonomi, kepribadian dan konsep diri, serta nilai dan gaya hidup pembeli4 . Karena banyak karakteristik ini memiliki dampak sangat langsung pada perilaku konsumen antara lain pekerjaan, gaya hidup dan kepribadian, maka penting bagi para pemasar untuk mengikuti mereka secara dekat.

PT. Daya Adicipta Wihaya sebagai salah satu perusahaan yang bergerak di bidang otomotif kendaraan roda empat yang bermerek Dagang DAIHATSU. Daya daihatsu merupakan anak perusahaan dari Daya Group dan Triputra Group yang didirikan dan memulai aktivitas pada bulan desember 2012 sebagai dealer resmi mobil Daihatsu dengan wilayah operasional Sumatera utara. Keunggulan mobil daihatsu yang paling paling menarik sebenarnya terletak pada penggunaan bahan bakar yang irit dan juga harga mobil yang terjangkau.

Berdasarkan hasil Pra survei yang dilakukan peneliti ke berbagai calon pembeli merek Daihatsu pada PT. Daya Adicipta Wihaya Medan calon konsumen lebih cenderung mempertimbangkan harga yang dalam kaitannya dengan merek mobil yang akan dibeli.

Fenomena dimana konsumen mengambil keputusan untuk membeli sebuah produk Mobil dengan merek Daihatsu di PT.Daya Adicipta Wihaya medan diduga erat kaitannya dengan faktor Harga dan Merek. Oleh karena itu penulis mengadakan untuk penelitian dengan Judul Pengaruh Harga dan Merek terhadap Keputusan Pembelian Mobil Daihatsu pada PT. Daya AdiciptaWihaya Medan.

\section{METODE PENELITIAN}

Penelitian ini dilakukan di PT Daya Adicipta Wihaya Medan Jl.Gagak Hitam Komp. Mega Bisnis CentreNo.11 Ringroad Medan. Menurut Sekaran (2006:77) populasi mengacu pada sekelompok orang, kejadian, atau hal minat 
P-ISSN $2580-7781$

E-ISSN 2615 - 3238

yang ingin peneliti investigasi. Populasi dalam penelitian ini adalah konsumen yang berjumlah sebanyak 69 orang.

Sampel adalah Subset dari populasi, terdiri dari beberapa anggota populasi. Dijadikan sampel, namun kesimpulannya dapat di generalisasikan untuk seluruh populasi adapun sampel penelitian ini adalah konsumen PT.Daya Adicipta Wihaya Medan. Menurut Arikunto (2002:11), apabila subjek penelitian populasi berjumlah kurang dari 100 lebih baik diambil semua sehingga penelitiannya merupakan penelitian populasi.

Berdasarkan ketentuan diatas maka jumlah sampel penelitian ini adalah berjumlah 69 orang (total sampling). Teknik pengambilan sampel dengan menggunakan metode sensus.

Sumber data dalam penelitian ini antara lain data yang bersumber dari PT Daya Adicipta Wihaya Medan, sampel yang diambil sebanyak 69 responden data yang diperoleh termasuk data sumber primer dan sumber sekunder yaitu:

1. Data primer (primary)

2. Data sekunder (library)

Metode pengumpulan data yang digunakan dalam penelitian ini adalah :

1. Penelitian Kepustakaan (Library Research)

2. Penelitian Lapangan

a. Angket (kuesioner)

b. Observasi (Pengamatan)

Menurut Umar (2002:316) untuk pengujian tingkat validitas instrumen dalam penelitian digunakan teknik analisis Koefisien Korelasi

$$
r_{x y}=\frac{\sum n X Y-\sum X \sum Y}{\sqrt{\left(n \sum X^{2}-\left(\sum X\right)^{2}\left(n \sum Y^{2}\right)-\left(\sum Y\right)^{2}\right)}}
$$

Dimana :

$r_{x y}=$ Koefisien korelasi pearson antara item instrumen yang akan digunakan dengan variabel yang bersangkutan

$\mathrm{X}=$ Skor instrumen yang akan digunakan

$\mathrm{Y}=$ Skor semua item instrumen dalam variabel tersebut 
P-ISSN $2580-7781$

E-ISSN 2615 - 3238

$\mathrm{n} \quad=$ Jumlah instrumen sementara

Setelah angka korelasi dihitung, kemudia dihitung nilai $\mathrm{t}$ dari $\mathrm{r}$ dengan rumus sebagai berikut :

$$
t=\frac{r \sqrt{(n-2)}}{\sqrt{1-r^{2}}}
$$

Setelah itu dibandingkan dengan kritiknya, bila $r$ hitung $>r$ tabel data tersebut signifikan (valid), sebalikmya bila $\mathrm{r}$ hitung $\leq \mathrm{r}$ tabel maka data tersebut tidak signifikan (tidak valid).

Pengujian reliabilitas instrumen dalam penelitian ini akan dilakukan secara internal. Sugiyono (2010:183) mengatakan bahwa : "Pengujian reliabilitas instrumen secara internal dapat dilakukan dengan menggunakan teknik belah dua kelompok (ganjil dan genap), ditotal, dicari korelasinya, dan kemudian dianalisis dengan rumus kofisien korelasi Spearman Brown, yang rumusnya adalah sebagai berikut :

$$
r_{1}=\frac{2 r_{b}}{1+r_{b}}
$$

Dimana :

$r_{1}=$ Reliabilitas internal seluruh instrumen

$r_{2}=$ Koefisien korelasi internal antara belahan ganjil dan genap

Untuk menguji keberartian koefisien $r_{x y}$ valid atau tidak akan digunakan uji t,yang dilakukan dengan membandingkan antara $t_{\text {hitung }}$ dengan $t_{\text {tabel }}$. Dimana $t_{\text {hitung }}$ dicari dengan menggunakan rumus dari Husein Umar (2002:316) sebagai berikut :

$$
t=\frac{r i \sqrt{(n-2)}}{\sqrt{1-r b^{2}}} ; \text { dengan } \mathrm{dk}=\mathrm{n}-2
$$

dimana $\mathrm{r}$ adalah koefisien korelasi Pearson dan $\mathrm{dk}$ adalah derajat bebas. Kesimpulan kuesioner penelitian dikatakan valid atau reliabel apabila $t_{\text {hitung }}>t_{\text {tabel }}$ dan sebaliknya tidak reliabel apabila $t_{\text {hitung }} t_{\text {tabel }}$. 
Dalam bukunya Sudaryanto ( 2003:43 ) mengemukakan suatu pengukuran disebut reliabel, bila memberikan nilai yang sama atau hampir sama pada pemeriksaaan berulang-ulang. Nilai koefisien reliabilitas yang baik adalah diatas 0,7 ( cukup baik ), di atas 0,8 ( baik).

Uji Asumsi Klasik adalah persyaratan statistik yang harus dipenuhi pada analisis regresi linear berganda yang berbasis ordinary least square (OLS). Setidaknya ada lima uji asumsi klasik, yaitu uji multikolinearitas, uji heteroskedastisitas, uji normalitas, uji autokorelasi dan uji linearitas.

Uji Normalitas digunakan untuk mengetahui apakah populasi data berdistribusi normal atau tidak.Uji ini biasanya digunakan untuk mengukur data berskala ordinal, interval, ataupun rasio.Jika analisis menggunakan metode parametrik, maka persyaratan normalitas harus terpenuhi yaitu data berasal dari distribusi yang normal.Jika data tidak berdistribusi normal, atau jumlah sampel sedikit dan jenis data adalah nominal atau ordinal maka metode yang digunakan adalah statistik non parametrik. Dalam pembahasan ini akan digunakan uji One Sample Kolmogorov-Smirnov dengan menggunakan taraf signifikansi 0,05. Data dinyatakan berdistribusi normal jika signifikansi lebih besar dari 5\% atau 0,05.

Uji Multikolinearitas digunakan untuk mengetahui ada atau tidaknya penyimpangan asumsi klasik multikolinearitas yaitu adanya hubungan linear antar variabel independen dalam model regresi.Prasyarat yang harus terpenuhi dalam model regresi adalah tidak adanya multikolinearitas. Ada beberapa metode pengujian yang bisa digunakan diantaranya yaitu 1) dengan melihat nilai inflation factor (VIF) pada model regresi, 2) dengan membandingkan nilai koefisien determinasi individual $\left(\mathrm{r}^{2}\right)$ dengan nilai determinasi secara serentak $\left(\mathrm{R}^{2}\right)$, dan 3$)$ dengan melihat nilai eigenvalue dan condition index. Pada pembahasan ini akan dilakukan uji multikolinearitas dengan melihat nilai inflation factor (VIF) pada model regresi dan membandingkan nilai koefisien determinasi individual $\left(\mathrm{r}^{2}\right)$ dengan nilai determinasi secara serentak $\left(\mathrm{R}^{2}\right)$. Menurut Santoso (2001:56), pada umumnya jika VIF lebih besar dari 5, maka variabel tersebut mempunyai persoalan Multikolinearitas dengan variabel bebas lainnya. 
Uji Heteroskedastisitas digunakan untuk mengetahui ada atau tidaknya penyimpangan asumsi klasik heteroskedastisitas yaitu adanya ketidaksamaan varian dari residual untuk semua pengamatan pada model regresi. Prasyarat yang harus terpenuhi dalam model regresi adalah tidak adanya gejala heteroskedastisitas.

Ada beberapa metode pengujian yang bisa digunakan diantaranya yaitu Uji Park, Uji Glesjer, Melihat pola grafik regresi, dan uji koefisien korelasi Spearman. Dalam hal ini Uji heteroskedastisitas dengan melihat pola titik-titik pada scatterplots regresi. Metode ini yaitu dengan cara melihat grafik scatterplot antara standardized predicted value (ZPRED) dengan studentized residual (SRESID).

Permasalahan yang akan dibahas adalah sejauh mana Pengaruh Harga dan Merek terhadap Keputusan Pembelian Mobil Daihatsu pada PT. Daya AdiciptaWihaya Medan. Dengan menggunakan analisis regresi berganda karena variabel dependent dipengaruhi dua variabel independent. Rumus matematikanya adalah sebagai berikut :

$$
\begin{aligned}
& \text { dimana: } \mathrm{Y}=\mathrm{a}+\mathrm{b}_{1} \mathrm{X}_{1}+\mathrm{b}_{2} \mathrm{X}_{2}+\varepsilon \\
& \mathrm{Y}=\text { Keputusan Pembelian } \\
& \mathrm{a}=\text { intercept } \\
& \mathrm{X}_{1}=\text { Harga } \\
& \mathrm{X}_{2}=\text { merek } \\
& \mathrm{b}=\text { Koefisien regresi. } \\
& \varepsilon=\text { standart error. }
\end{aligned}
$$

Sedangkan untuk menganalisa model tersebut dilakukan pengujian sebagai berikut: Uji t digunakan untuk mengetahui apakah variabel independen secara parsial mempunyai pengaruh yang signifikan terhadap variabel dependen. Uji statistik t digunakan untuk mengetahui seberapa jauh pengaruh satu variabel independent secara individual dalam menjelaskan variasi variabel dependent Ghozali (2006:42).Apabila nilai probabilitas signifikansi $<0.05$, maka suatu variabel independent merupakan penjelas yang signifikan terhadap variabel dependen. 
P-ISSN 2580 - 7781

E-ISSN 2615 - 3238

\section{HASIL PENELITIAN DAN PEMBAHASAN}

\section{DAYA DAIHATSU}

Member of Daya Group

Berdiri pada tahun 2012, PT. Daya Adicipta Wihaya atau lebih dikenal dengan DAYA Daihatsu merupakan anak perusahaan DAYA Group yang bergerak di bidang dealership kendaraan roda empat dengan merek Daihatsu.

Saat ini DAYA Daihatsu memiliki 2 cabang yang berlokasi di Jakarta Barat dan Medan. Sejalan dengan visi, misi dan value perusahaan, DAYA Daihatsu terus meningkatkan kapasitas penjualan, kualitas layanan dan sumber daya manusia di seluruh cabang. Semua itu dilakukan agar DAYA Daihatsu dapat menjadi sahabat masyarakat dalam menyediakan kepemilikan mobil Daihatsu.

Sebagai subsidiary company dari DAYA Group, DAYA Daihatsu merupakan bagian dari PT Triputra Investindo Arya (Triputra Group).Triputra Group berdiri sejak tahun 1998, didirikan oleh Bapak Theodore Permadi Rachmat. Dengan motto perusahaan "Excellence through People and Process", Triputra Group telah dinominasikan sebagai salah satu dari 8 group terbesar di Indonesia menurut Globe Asia Survey pada tahun 2014.

Saat ini Triputra Group memiliki karyawan lebih dari 40.000 orang yang tersebar di sejumlah anak perusahaaan yang bergerak di bidang manufaktur, pertambangan, agri bisnis, penjualan \& jasa. Sementara DAYA Group sendiri merupakan sub-holding dari Triputra Group yang bergerak dalam industri penjualan dan jasa. Beberapa perusahaan dalam DAYA Group sudah lama dikenal dalam industri otomotif terutama sebagai Main Dealer dan Dealership, khususnya untuk sepeda motor Honda. Saat ini DAYA Group telah berkembang ke industri otomotif roda empat, agro bisnis, jasa kesehatan dan properti. Visi PT Daya Adicipta Wihaya Medan "To Be The Best Daihatsu Dealer In Indonesia Before 2020" Misi PT Daya Adicipta Wihaya Medan "Servicing Customer As A Friend" 
P-ISSN 2580 - 7781

E-ISSN 2615 - 3238

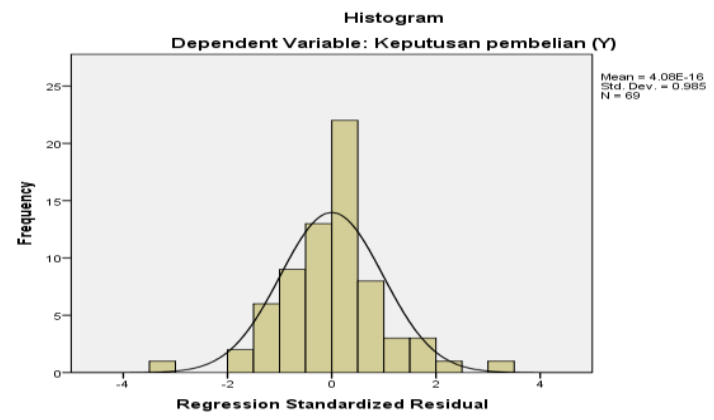

Gambar 1. Grafik Histogram

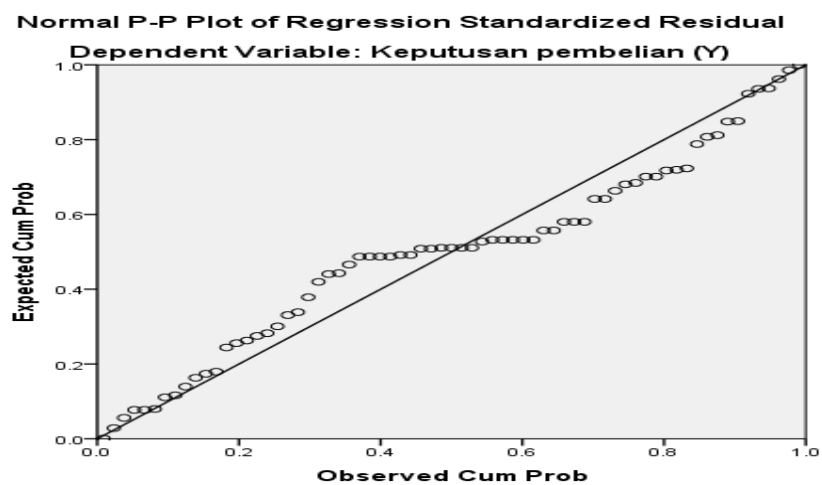

Gambar 2. Uji Normalitas.

Berdasarkan gambar pada histogram maupun normal probability plot. Dapat dilihat bahwa pada normal probability plot ada penyebaran titik-titik disekitar garis diagonal dan penyebarannya mengikuti arah garis diagonal, hal ini berarti data tersebar berdistribusi normal.

\section{Uji Multikolinieritas}

Tabel. Uji Multikolonieritas

Coefficients ${ }^{\mathrm{a}}$

\begin{tabular}{|l|r|r|}
\hline \multirow{2}{*}{ Model } & \multicolumn{2}{|c|}{ Coefficients } \\
\cline { 2 - 3 } & Collinearity \\
\hline (Constant) & Tolistics \\
Harga (X1) & .517 & VIF \\
Merek (X2) & .517 & 1.933 \\
& & 1.933 \\
\hline
\end{tabular}

a. Dependent Variable: Keputusan pembelian (Y)

Dari tabel diatas dapat dilihat bahwa nilai VIF dari Harga (X1) dan Merek (X2) memiliki masing-masing nilai VIF lebih kecil dari pada 10 (VIF <10). Untuk 


\section{P-ISSN $2580-7781$}

E-ISSN 2615 - 3238

nilai Tolerance masing-masing variable nilai Tolerance<1.Dengan demikian, dapat disimpulkan bahwa tidak terjadi gejala multikolinearitas.

Berdasarkan tabel diperoleh $\mathrm{t}$ hitung sebesar 1.936. Tabel distribusi $\mathrm{t}$ dicari pada $\alpha=5 \%$ diperoleh untuk $\mathrm{t}$ tabel sebesar 0.67933. Nilai $\mathrm{t}$ hitung $>\mathrm{t}$ tabel $(1.936>0.67933)$. Oleh karena nilai $t$ hitung $>t$ tabel $(1.936>0.67933)$ maka Ho ditolak, artinya secara parsial ada pengaruh signifikan antara Merek $\left(\mathrm{X}_{2}\right)$ dengan Keputusan Pembelian (Y). Jadi dari kasus ini dapat disimpulkan bahwa secara parsial Merek berpengaruh terhadap Keputusan Pembelian Mobil Daihatsu pada PT. Daya Adicipta Wihaya Medan.Berdasarkan tabel diperoleh F hitung sebesar 65.915. Dengan menggunakan tingkat keyakinan 95\%, $\alpha=5 \%$, diperoleh untuk $F$ tabel sebesar 3.14.Nilai $F_{\text {hitung }}>F_{\text {tabel }}(65.915>3.14)$, maka Ho ditolak.Karena $F_{\text {hitung }}>F_{\text {tabel }}$ Nilai $F$ hitung $>F_{\text {tabel }}(65.915>3.14)$, maka Ho ditolak, artinya ada pengaruh secara signifikan antara (harga dan Merek ) secara bersama-sama terhadap variabel dependen (Keputusan Pembelian). Berdasarkan tabel di atas diperoleh angka $\mathrm{R}^{2}$ (R Square) sebesar 0,666 atau (66,6\%). Hal ini menunjukkan bahwa presentase sumbangan pengaruh variabel independen (Harga dan Merek ) terhadap variabel dependen (Keputusan pembelian ) sebesar 66,6\%. Atau variasi variabel independen yang digunakan dalam model (Harga dan Merek) mampu menjelaskan sebesar 66,6\% variasi variabel dependen (Keputusan pembelian). Sedangkan sisanya sebesar $23,4 \%$ dipengaruhi atau dijelaskan oleh variabel lain yang tidak dimasukkan dalam model penelitian ini.

\section{Uji Heteroskedastisitas}

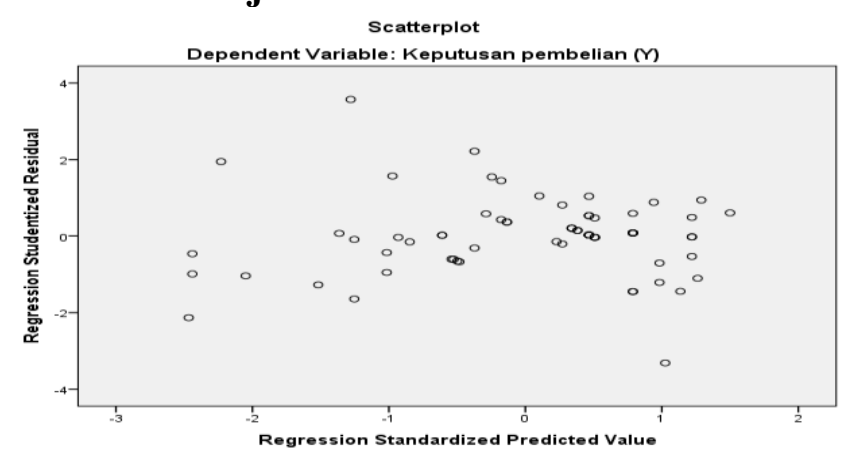

Gambar 4. Heterokedastisitas 
P-ISSN $2580-7781$

E-ISSN 2615 - 3238

Dari gambar terlihat bahwa titik-titik menyebar secara acak, baik di bagian atas angka nol atau di bagian bawah angka 0 dari sumbu vertical atau sumbu Y. dengan demikian, dapat disimpulkan bahwa tidak terjadi heterokedatisitas dalam model regresi ini.

Berdasarkan tabel diperoleh $\mathrm{t}_{\text {hitung }}$ sebesar 7.506. Tabel distribusi t dicari pada $\alpha=5 \%$ diperoleh untuk $t$ tabel sebesar 1.66792. Nilai $t$ hitung $>t$ tabel (7.506>(1.66792) maka Ho ditolak. Oleh karena nilai $t$ hitung $>t$ tabel (7.506> 1.66792) maka Ho ditolak, artinya secara parsial ada pengaruh signifikan antara Hargadengan Keputusan pembelian. Jadi dari kasus ini dapat disimpulkan bahwa secara parsial Harga berpengaruh terhadap Keputusan Pembelian Mobil Daihatsu pada PT. Daya Adicipta Wihaya Medan

\section{KESIMPULAN}

Berdasarkan analisis yang dilakukan, maka kesimpulan dari penelitian ini adalah Penelitian ini menggunakan dua variabel independen yaitu harga dan merek yang berpengaruh terhadap variabel dependen yaitu keputusan pembelian penelitian ini juga secara terbatas menjelaskan adanya hubungan variabel harga dan merek yang secara parsial dan signifikan mempengaruhi keputusan pembelian sebesar sehingga hubungan antara variabel harga dan merek terhadap keputusan pembelian cukup erat. Oleh karenanya dalam pengembangannya pihak perusahaan dengan melakukan pertimbangan terhadap harga dalam menjual produk sehingga diharapkan konsumen memiliki informasi yang jelas dalam mengambil keputusan dalam pembelian produk, untuk menjadikan minat keputusan pembelian konsumen sebaiknya perusahaan mempertimbangkan merek dalam menjual produk sehingga diharapkan konsumen memiliki informasi yang jelas dalam mengambil keputusan dalam pembelian produk. Konsumen sebaiknya mempelajari dan mencari informasi yang jelas mengenai harga dan merek suatu produk dalam mengambil keputusan untuk melakukan pembelian. 
P-ISSN 2580 - 7781

E-ISSN 2615 - 3238

\section{DAFTAR PUSTAKA}

Abdullah, Thamrin dan Francis Tantri.2012.Manajemen Pemasaran. Jakarta: PT. Raja Grafindo Persada.

Adrianto, Noky Hendra dan idris. 2013. Pengaruh kualitas produk, citra merek, harga dan promosi terhadap keputusan pembelian mobil jenis MPV merek toyota kijang innova di semarang. Jurusan manajemen fakultas ekonomika dan bisnis universitas diponegoro, volume 2, Nomor 3 tahun 2013, halaman 1-10 tanggal akses 10 nopember 2015

Alma, Buchari. (2014). Manajemen Pemasaran dan Pemasaran Jasa. Bandung: Alfabeta.

Arikunto, S. 2010. Prosedur penelitian: Suatu Pendekatan Praktik. (Edisi Revisi). Jakarta : Rineka Cipta

Edy, Sutrisno. 2012. Manajemen Sumber Daya Manusia. Jakarta: Kencana

Ferrinadewi, Erna. 2008. Merek dan Psikologi Konsumen. Jakarta: Graha Ilmu

Ghozali, Imam, 2006. Aplikasi Analisis Multivarite dengan SPSS, Cetakan Keempat, Badan Penerbit Universitas Diponegoro, Semarang.

Kasmir, 2012. Manajemen Pemasaran. Jakarta : Gramedia Pustaka.

Kotler dan Armstrong, 2012. Marketing Manajemen Edisi 14. Global Edition.Pearson Pretince Hall.

Mulyadi, Dedi dkk. 2012. Analisis merek terhadap keputusan pembelian kartu perdana AS di SMA N S Karawang. Jurnal Manajemen, Vol. 10, No 1, oktober 2012, Hal 993-1001. Tanggal akses 10 Nopember 2015.

Stanton, Robert. 2007. Teori Fiksi. Yogyakarta: Pustaka Pelajar

Sugiyono, 2008. Metode Penelitian Bisnis. Cetakan Keduabelas. Bandung: Alfabeta.

Supriadi, Victor. 2013. Kualitas produk, merek dan harga pengaruhnya terhadap keputusan pembelian konsumen pada percetakan Mitra Card di Manado. Jurnal EMBA, Vol.1, No.4

Tjiptono, Fandy. (2014). Pemasaran Jasa. Jakarta: Gramedia Cawang. 